\title{
Investigation into the Changes in Bending Stiffness of a Textile Reinforced Composite due to In-Plane Fabric Shear: Part 2 - Numerical Analysis
}

\author{
Cynthia Mitchell, Lisa Dangora, Christie Bielmeier, James Sherwood* \\ Department of Mechanical Engineering, University of Massachusetts Lowell \\ One University Ave., Lowell, MA 01854, USA
}

*Corresponding Author james_sherwood@uml.edu

\begin{abstract}
Numerical investigations were pursued in an effort to understand the relationship between changes in the stiffness of plain-weave fabric-reinforced plates and the degree of in-plane shear within the fabric reinforcement. These numerical studies were motivated by an experimental study where the measurable geometric changes discerned among plates with different levels of in-plane shear were (1) the reorientation of the fibers within the plane of the plate, (2) an increase in

thickness with increasing in-plane shear, and (3) the change in width of the fiber tows as function of in-plane shear. Finite element models were used to investigate the individual contributions of these geometric changes on the bending stiffness of the plates. For the material system considered in this study, the reorientation of the fibers and the change in plate thickness as a function of the state of shear were concluded to be the dominant factors affecting the bending stiffness of the plates. The change in cross-section orientation about the tow axis was determined to be insignificant.
\end{abstract}

\section{Keywords}

A. Fabrics/textiles; B. Mechanical Properties; C. Laminate Mechanics; D. Shear Deformation 


\section{INTRODUCTION}

Fiber-reinforced composites are becoming popular materials across a wide spectrum of industries [1-4] due to their high specific-strength and specific-stiffness characteristics [5-7]. Textile-reinforced composites are particularly attractive for their potential to save time during the manufacture of composite structures. Automated manufacturing techniques, such as thermoforming, compression molding, and hydroforming, have the ability to transform a two-dimensional textile into a three-dimensional structure within one manufacturing step [8-10].

As the fabric conforms to complex three-dimensional molds, there are three major modes of deformation occurring within the textile: the tows can stretch, the fabric can shear, and the tows can bend in-plane and out-of-plane. Many researchers have devoted time and effort to understand this shear deformation during the forming of composite structures [11-20]. The current paper will solely examine shear dominated phenomena. When the fabric shears, the tows that were originally mutually perpendicular rotate within the plane of the fabric, thereby resulting in non-orthogonal fiber orientations. An example of this deformation is illustrated by a hemisphere formed from a plain-weave fabric as depicted in Fig. 1. Many researchers have presented finite element models that consider the mechanical behavior of the textile during the manufacture of a composite structure to predict the final orientations of the fiber tows [21-37]. These simulations aid in the design of molds used to form the material and to assist in the selection of fabrics to satisfy the drapability requirements of the part geometry. However, little research exists in the open literature linking the results of these forming models to the structural behavior of the composite part.

The current research is part of an introductory study directed at developing a fundamental understanding of the effect of sheared fabric-reinforcements on the stiffness of composite plates, which is presented as a two-part series. Such a study is the first step necessary to link the results of 
the robust forming models presented in the literature to the mechanical properties of the composite. In Part 1, the effects of in-plane shear on the flexural behavior of textile-reinforced composite plates were examined using an experimental approach, and the manufacture of the plates with various degrees of in-plane shear within the textile reinforcement was discussed in detail [38]. In Part 2, the respective significances of the geometric changes within the plates caused by the shearing of the fabric reinforcements are investigated using a numerical approach. These geometric changes include (1) the reorientation of the fibers within the plane of the plate, (2) an increase in thickness with increasing in-plane shear, and (3) the change in width of the fiber tow as a function of in-plane shear. The numerical approach allows for examining the significance of the contribution made by each of the three geometric changes to the effective bending stiffness of each plate. The current study will provide a fundamental understanding of what geometric attributes must be captured by the manufacturing simulation to use the results to calculate the mechanical behavior of the composite. Additionally, the current work will demonstrate what attributes are necessary in a robust composite material model that accurately depicts the behavior of textile-reinforced composites. The results of this study will allow researchers to connect the structural composite model back to the forming simulation, thereby linking the stiffness of the final consolidated part back to the manufacturing processing conditions.

\section{Critical Investigation of the Factors Influencing Flexural Stiffness of Sheared Plates}

Part 1 of this investigation [38] described the manufacture of composite plates reinforced by textiles with various degrees of in-plane shear. The current work will refer to two coordinate systems defined by the plates' geometries, as depicted in Fig. 2. The global XY coordinate system remains parallel to the edges of the composite plate. In plates reinforced by undeformed textiles, the $\mathrm{X}$-axis is parallel to the weft tows and the $\mathrm{Y}$-axis is parallel to the warp tows. The global $\mathrm{XY}$ axis is 
independent of the degree of shear in the textile reinforcement and the axes remains perpetually orthogonal. The local $x y$ coordinate system follows the orientations of the tows within the plate and is dependent on the shear angle, $\gamma$, in the fabric reinforcement. The local $x$-axis remains parallel with the weft tows and the local $y$-axis remains parallel with the warp fibers. The plates considered in the current work were cut such that the weft fibers remained parallel with the edge of the plates, i.e. the global X-axis and local $x$-axis remained parallel.

The load-displacement curves for flexure tests performed in Part 1 of the analysis [38] are depicted in Fig. 3(a) and Fig. 3(b). The respective slopes of the load-displacement curves, shown in Fig. 3(c) and Fig. 3(d), are directly proportional to the stiffness of the plate in each global direction. The increase in stiffness in the X-direction as the shear angle within the reinforcement increased was expected. However, the plates that were bent in the Y-direction did not follow the expected trend, i.e. a drop in stiffness as the warp tows rotated toward the weft tows. In an effort to understand this phenomenon, a critical investigation of the potential factors leading to this contradiction was pursued in the current study. Additionally, geometric changes in the textilereinforcement were observed as a function of in-plane shear. Most notably, the thickness of the plate increased as the fabric shear angle increased, and the width of the fiber tows decreased as the shear angle increased.

The current investigation began by considering Classical Laminate Theory (CLT) to explore the mechanics of an anisotropic plate in flexure. This application of CLT lead to exploring how the geometric changes observed as a function of textile shear contributed to the effective flexural stiffness. 


\subsection{Application of Classical Laminate Theory}

CLT relates applied loads on a laminate to the associated stresses, strains, and deflections of the composite structure [6]. The application of CLT is generally limited to composites reinforced by layers of unidirectional fibers with a constant fiber volume fraction. Composites reinforced by textile-reinforced composites are difficult to analyze due to the internal geometry of the reinforcements. However, some relations can be used to analyze the global behavior of the composite. The laminate's global stiffness matrix, commonly referred to as the ABD matrix, relates the strains experienced by the geometric midplane of the composite to the applied loads through the following relations in the global coordinate system defined in Fig. 2:

$$
\left\{\begin{array}{c}
N_{X} \\
N_{Y} \\
N_{X Y} \\
M_{X} \\
M_{Y} \\
M_{X Y}
\end{array}\right\}=\left[\begin{array}{llllll}
A_{11} & A_{12} & A_{16} & B_{11} & B_{12} & B_{16} \\
A_{12} & A_{22} & A_{26} & B_{12} & B_{22} & B_{26} \\
A_{16} & A_{26} & A_{66} & B_{16} & B_{26} & B_{66} \\
B_{11} & B_{12} & B_{16} & D_{11} & D_{12} & D_{16} \\
B_{12} & B_{22} & B_{26} & D_{12} & D_{22} & D_{26} \\
B_{16} & B_{26} & B_{66} & D_{16} & D_{26} & D_{66}
\end{array}\right]\left\{\begin{array}{c}
\varepsilon^{o}{ }_{X} \\
\varepsilon_{Y}^{o} \\
\gamma_{X Y}^{o} \\
\kappa_{X}^{o} \\
\kappa_{X}^{o} \\
\kappa_{Y}^{o}{ }_{X Y}^{O}
\end{array}\right\}
$$

All of the plates in the current study were reinforced by a single-ply of a plain-weave fabric [38]. Three-point-bend tests performed on the plates resulted in similar curvatures for equivalent positive and negative moments, confirming symmetry of the specimens about the neutral surface. Therefore, by definition of a symmetric laminate, extensions and bending are uncoupled (i.e., $B_{i j}=$ 0 ). No external strains were applied to the plate, thus the strains experienced at the plate's neutral axis are $\varepsilon_{X}^{o}=\varepsilon_{Y}^{o}=\gamma_{X Y}^{o}=0$, in the absence of any internal stresses. The bend tests were displacement-controlled experiments, resulting in a primary curvature about one axis of the plate, i.e. $\kappa_{X}^{o} \neq 0$ for a bend about the $X$-axis. The boundary conditions of the three-point-bend test prevent the curvature of the neutral axis about the opposite axis, i.e. $\kappa_{Y}^{o}=0$. While a twisting of the plate is not necessarily inhibited by the boundary conditions of the test setup, it is limited by the supports and no visible twisting was observed during the tests. Thus, the curvature of the plate about 
the X-direction can be considered the primary deformation, while any twisting curvature can be assumed to be negligible, i.e. $\kappa_{X Y}^{o} \approx 0$. Therefore, the resultant forces can be simplified from Eqn. 1

to:

$$
\begin{aligned}
& M_{x}=D_{11} \kappa_{X}^{o} \\
& M_{y}=D_{12} \kappa_{X}^{o} \\
& M_{x y}=D_{16} \kappa_{X}^{o}
\end{aligned}
$$

These plates will experience a bending moment, $M_{X}$, from the enforced curvature, $\kappa_{X}$. Additionally, the specimens will experience a second bending moment, $M_{Y}$, resulting from the Poisson effect as well as a twisting moment, $M_{X Y}$, due to the bend-twist coupling present in composites. Note that a special case exists for the plates with $0^{\circ}$ shear angles since they are classified as cross-ply laminates, so by definition, $D_{16}=0$. The geometric deformations observed in the Part 1 paper [38] have the potential to affect the stiffness constants $D_{11}, D_{12}$, and $D_{16}$. The following sections examine how the bending stiffness of composite plates are affected by (1) the change in the thickness of the laminate and (2) the change in the geometry of the cross-section of the fiber tow as a result of shearing the reinforcement.

\subsection{Effect of Thickness on Bending Stiffness}

One factor that affects the bending stiffness of the plates is thickness. Eqns. 2 to 4 cite the three constants that relate the moments applied to the plate to the resulting curvature. For a singleply plate, the flexural stiffness constants, $D_{11}, D_{12}$, and $D_{16}$ are defined in CLT as:

$$
\begin{gathered}
D_{11}=\frac{1}{4} \bar{Q}_{11} t^{3} \\
D_{12}=\frac{1}{4} \bar{Q}_{12} t^{3} \\
D_{16}=\frac{1}{4} \bar{Q}_{16} t^{3} .
\end{gathered}
$$


While the woven-textile geometry makes the calculation of the $\bar{Q}_{i j}$ matrix difficult, Eqns (5)

through (7) demonstrate each of these flexural stiffness constants is directly proportional to the cube of the plate thickness.

Fig. 4 illustrates that the thickness of the fabric-reinforced plates increased with increasing fabric shear. To effectively remove the contribution of thickness from the stiffness data, i.e. normalize the data with respect to thickness, the average of the measured load-displacement slopes that are reported in Fig. 3 were divided by the cube of the average measured plate thicknesses depicted in Fig. 4. The normalized load-displacement slopes for the X-direction are shown in Fig. 5(a) and for the Y-direction in Fig. 5(b). The results indicate that as the shear angle increases, the normalized slope in the X-direction remains relatively constant with large scatter in the data. Conversely, the normalized slope in the Y-direction decreases as the shear angle within the fabric increases. While the results from Fig. 5(a) do not demonstrate a discernable trend, the trends shown in Fig. 5(b) were expected due to the reorientation of the fibers within the plate.

\subsection{Effect of Tow Cross-Section Shape and Orientation on Bending Stiffness}

Another geometric change observed to be dependent on the degree of shear in the textile reinforcement was the width of the fiber tows. This observation implies the geometry of the tow is changing as a function of in-plane shear. The specific textile considered in this research contains glass fibers. Due to their long, slender geometry, these tows can be analyzed using beam theory. The effective bending stiffness of the plate is dependent on the sum of the individual contributions of the respective area moment of inertia, $I$, and the torsional constant, $J$, for each of the tows comprising the plate. These stiffness parameters are important to understanding the bend-twist

coupling that the sheared plates will experience and are a function of (1) the cross-sectional shape of the tow and (2) the orientation of the tow about its longitudinal axis. The following subsections will 
investigate the geometric changes of the tows as a function of in-plane shear and determine the contribution these changes have on the bending stiffness of the fibers.

\subsubsection{Visual Investigation of Tow Cross-Section Shape and Orientation}

An edge of each tested plate was cut parallel to the global Y-axis and polished to allow for a visual inspection of the tow cross-sections. This cut will henceforth be referred to as the Y-Y crosssection. Images of the cross-sections were taken on a Zeiss V20 Stereo Microscope. A representative set of Y-Y cross-sections from the $0^{\circ}$ (no-shear) plates is given in Fig. 6(a). An outline of the tow cross-section is shown in Fig. 6(b). The respective cross-sectional shapes of the fiber tows are relatively similar throughout the plate.

Additional images illustrated that as the shear angle increased, the similarity between the tows decreased and the shapes of the fiber tows began to change throughout the plate. An example of this deformation is illustrated by Y-Y cross-sections of the $25^{\circ}$-shear plates as shown in Fig. 7(a). An outline of the tow cross-section is shown in Fig. 7(b). The bottom image in Fig. 7(a) shows two adjacent fiber tows. While the tow on the left has approximately the same shape as the fiber tows depicted in Fig. 6(a), the tow on the right is rotated such that it spans from the top of the plate to the bottom of the plate. This rotation of the tow Y-Y cross-section can potentially have a measurable influence on the effective bending and torsional stiffnesses of the "beam" reinforcements to the overall effective stiffness of the sheared plate. However, it is difficult to experimentally quantify the influence of the Y-Y cross-section on the plate's bending stiffness due to the multitude of factors that contribute to the bending stiffness of a composite plate. To isolate the rotation of the Y-Y crosssection, first, the geometry behind the rotation must be understood. Then, a discrete finite element model can be used to investigate if this change in geometry impacts the stiffness of the composite. 


\subsubsection{Modeling of the Tow Cross-Section Shape and Orientation}

A geometric model was created based on the equations presented by Barbero [39] and programmed using MATLAB. To keep the geometric model relatively simple, the midsurface, or geometric neutral axis, of each tow was considered instead of the entire cross-section. A plot of a Representative Volume Element (RVE) comprised of the midsurfaces of each tow is shown in Fig. 8. The undulation in the z-direction (i.e. the axis normal to the plane of the plate) of the weft tows along the $x$-axis, $z_{f}$, can be described as:

$$
z_{f}(x, y)=-\frac{t-h_{f}}{2} \cos \frac{\pi x}{w_{w}+g_{w}}
$$

where $t$ represents the overall thickness of the fabric, $h_{f}$ represents the height of the weft tows, $w_{w}$ represents the width of the warp tows, and $g_{w}$ represents the gap between the warp tows. Similarly, the undulations in the z-direction of the warp tows along the $y$-axis, $z_{w}$, can be defined as:

$$
z_{w}(x, y)=\frac{t-h_{w}}{2} \cos \frac{\pi y}{w_{f}+g_{f}}
$$

where $h_{w}$ represents the height of the warp tows, $w_{f}$ represents the width of the weft tows, and $g_{f}$ represents the gap between the weft tows.

When the fabric is in the undeformed state, the local and global coordinate systems are coincident (Fig. 2(a)). As the fabric shears, the respective axes of the local and global coordinate systems are no longer parallel (Fig. 2(b)). For the plates considered in this study, the fabric reinforcement was sheared such that the local $x$-axis and global X-axis remained parallel, and the local $y$-axis was rotated from the global Y-axis by the prescribed shear angle, $\gamma$. Therefore, the transformation from the local coordinate system to the global coordinate system can be calculated as:

$$
\begin{gathered}
\mathrm{X}=x+y \sin \gamma \\
\mathrm{Y}=y \cos \gamma
\end{gathered}
$$


Eqns. 8 and 9 describe the undulation of the tows in the local coordinate system. To understand how the tows behave in the global coordinate system, they are combined with Eqns. 10 and 11 to produce:

$$
\begin{aligned}
& z_{f}(\mathrm{X}, \mathrm{Y}, \gamma)=-\frac{t-h_{f}}{2} \cos \frac{\pi(\mathrm{X}-\mathrm{Y} \tan \gamma)}{w_{w}+g_{w}} \\
& z_{w}(\mathrm{X}, \mathrm{Y}, \gamma)=\frac{t-h_{w}}{2} \cos \frac{\pi \mathrm{Y}}{\left(w_{f}+g_{f}\right) \cos \gamma}
\end{aligned}
$$

Eqns. 12 and 13 can be used to calculate the out-of-plane position of a point on a tow as a function of the shear angle present in the woven fabric.

\subsubsection{Calculated Tow Twist}

Eqns. (12) and (13) indicate the fiber undulations calculated in the global XY coordinate system are dependent on the width of the fiber tows. The Part 1 paper [38], which contained the experimental portion of the study, compared the measured width of the tows within the plate to the shear angle within the fabric reinforcements. Note that the width of the fiber tow, $w$, was measured in the global coordinate system on the global Y-Y cross-section, depicted in Fig. 9(a). Similarly, a cut can be made parallel to the local $y$-axis to observe the local $y-y$ cross-section, shown in Fig. 9(b). The geometric relationship between the two cross-sections is shown in Fig. 9(c).

The experimental measurements were compared to predicted tow widths calculated as a function of fabric shear angle using equations developed by Zhu et al. [20] and McBride and Chen [40]. This comparison can be seen in Fig. 10. The equation presented by McBride and Chen considers lateral compaction of the fiber tow, while the equation presented by Zhu et al. does not consider compaction and is based purely on a geometric deformation model, i.e. $w_{0}$ is not a function of shear angle. The correlation of the experimental data in Fig. 10 with the "w/o Compaction" model indicates that there is no lateral compaction of the tows for the fabric considered in this study. 
Thus, the measured change in width can be attributed to shearing of the fiber tow as illustrated in

Fig. 9(c). The width of a tow in the sheared plate can be described by the equation:

$$
w=w_{0} \cos \gamma
$$

The local $y$-y cross-sectional shape of the fiber tow remains unchanged as the fabric shears, but the $y$-y cross-section is rotated away from its original orientation about the Z-axis. However, the Y-Y cross-section will change as a function of in-plane shear, as demonstrated in Fig. 7.

Eqn. 12 can be used to describe the midsurface of the weft tows as a function of the coordinates of a point and the shear angle within the fabric. Fig. 11 shows how the shape and vertical position of the $\mathrm{Y}-\mathrm{Y}$ cross-section centerline change as a function of the position along a tow over one undulation period. Each row in Fig. 11(b) is for a different fabric shear angle. Each column corresponds to a different position along the undulation period indicated by the vertical lines in Fig. 11(a). When there is no in-plane shear $\left(0^{\circ}\right.$, top row of Fig. 11(b)), the only change along an undulation period is the vertical position of the cross-section. When the fabric is sheared, the deformation of the tow causes the perpendicular cross-section to change shape. The shape changes as a function of shear as well as along the length of the tow. At any fixed position along the length of the tow, the amount of deformation increases with increasing shear angle. The trends demonstrated by the mathematical modeling result agrees with the observed Y-Y cross-section deformation trends seen experimentally, e.g. Fig. 6 and Fig. 7. As the shear angle in the fabric reinforcement increases, the deformation becomes more pronounced.

\subsubsection{Tow Twist Implemented into the Beam-Shell Model of a Sheared Plate}

To assist in developing an understanding of the geometric effects of fabric shear, a discrete finite element model of the plates, known as the beam-shell model (Fig. 14), was utilized. This approach uses a mixed-mesh unit cell approach in which isotropic beam elements represent the fiber 
tows and isotropic shell elements represent the matrix. This mesh is advantageous for this study because the model can compare the effective stiffnesses of the plate with undeformed beam reinforcements to the effective stiffnesses of the plate with the observed tow deformations. The beam-shell approach of discretizing the contributions of the resin and the fiber reinforcements from the overall composite is described in detail by Mitchell et al. [37].

The ultimate goal of this research is to implement the deformations observed in Fig. 11 into a beam element for completing structural analyses, e.g. stiffness and modal responses of a composite structure where the fabric reinforcement has deformed as a result of the manufacturing process. An accurate beam-shell model would implement the global Y-Y cross-section (Fig. 11) as the beam element's cross-section. However, a beam element is generally represented by a relatively simple cross-sectional shape. Therefore, the cross-sectional shape of the sheared tow will be approximated by an ellipse that is simply twisted about the centerline of the tow, $\mathrm{Y}=0$, along the length of the fiber, X. A schematic illustrating this concept can be seen in Fig. 12. The blue line in Fig. 12 is the midplane of the cross-section that corresponds to the second column of the $30^{\circ}$ row in Fig. 11. The red line in Fig. 12 is the approximation to be implemented into the beam element. The effective twist of the cross-section, $\phi$, can be approximated by a trigonometric relationship between the change in height of the cross section calculated by Eqn.12 over the width of the fiber tow calculated by Eqn. 14:

$$
\phi(\mathrm{X}, \gamma)=\tan ^{-1}\left(\frac{z_{f}\left(\mathrm{X}, w_{f} / 2, \gamma\right)-z_{f}\left(\mathrm{X},-w_{f} / 2, \gamma\right)}{w(\gamma)}\right)
$$

Eqn. 12 is evaluated for the edges of the tow, $\mathrm{Y}=w_{f} / 2$ and $\mathrm{Y}=-w_{f} / 2$. Eqns. 14 and 16 are substituted into Eqn. 15, and are then simplified to yield:

$$
\phi(X, \gamma)=\tan ^{-1}\left(\frac{\left(h_{f}-t\right) \sin \left(\frac{\pi \mathrm{X}}{w_{w}+g_{w}}\right) \sin \left(\frac{\pi w_{f_{0}} \sin \gamma}{2\left(w_{w}+g_{w}\right)}\right)}{w_{f_{0}} \cos \gamma}\right) .
$$


Eqn. 16 was evaluated for values of $\mathrm{X}$ along the length of an undulation period and plotted in Fig. 13(a). The twist demonstrates a sinusoidal relationship with respect to the length of the tow. One undulation of the tow corresponds to the period of the sinusoid. To implement the deformations of the tow due to the tows shearing in a finite element model, a further simplification was made to describe the rotation as plotted in Fig. 13(a). One tow undulation corresponds to the length of two fabric unit cells. To implement the twist of the cross-section into the model, the twist angle was averaged over a unit cell using a root mean square average. The average twist angle is shown in Fig. 13(b).

In the current research, the tows were modeled both with and without the observed twist calculated from Eqn. 18. The model was used with material properties provided from the manufacturer [41] and the measured dimensions. These properties and dimensions are given in Table 1. Beam-shell models were generated for plates in which the fabric reinforcement had been sheared $0^{\circ}, 10^{\circ}, 20^{\circ}, 25^{\circ}$, and $30^{\circ}$ - the same as the plates tested in the Part 1 paper [38].

Finite element models of the plates were subjected to a three-point-bend test about the global X-axis and the global Y-axis using Abaqus/Standard. Each model was investigated with and without the estimated twist implemented into the beam cross-section definition. The slopes of the resulting load-displacement curves are reported in Fig. 15. While neither modeling approach demonstrates the trends that were seen experimentally, there is no significant difference between the results of the two modeling approaches. While the slopes of the finite element models change as a function of shear within the fabric reinforcement, the twisting deformation of the fiber tow does not have a measurable influence on the bending stiffness. The width of the fiber tows is approximately 10 times greater than the thickness of the plate. Therefore, a simple calculation yields the maximum 
twist angle that can occur in the plate is about $6^{\circ}$, which is not enough to significantly affect the bending stiffness of the plate.

\section{DISCUSSION}

The current work has major implications for modeling the forming processes of textilereinforced composites and subsequent finite element analyses of the consolidated composite part. The change in textile thickness as a function of in-plane shear is a critical factor in the stiffness of the overall composite. Therefore, thickness changes resulting from in-plane shear deformation should be represented in forming simulations of textile composites. If the part thickness is correctly predicted by forming simulations, the stiffness of the consolidated composite can be properly formulated in subsequent structural analyses.

Additionally, the present work demonstrates that the composite stiffness does not depend on the shape of the fiber tows. This observation is an important revelation for development of a finite element model representing the structural composite part. If the cross-sectional shape and orientation of the fiber tows were important factors in the stiffness of the composite, the most accurate method to model a composite structure would require the fiber tows to be represented as discrete elements, similar to the beam-shell model. However, the findings of the current study indicate the individual constituents can be homogenized into a single material model. Homogenizing the properties of the constituents is the most common way to represent fiberreinforced composite materials. The current study indicates a similar methodology can be developed to model textile-reinforced composite materials.

The current introductory study indicates the changes in fabric geometry influence the mechanical behavior of composite materials reinforced by textiles with in-plane shear present in the fabric. However, the current study only considers pure shear deformations on unconstrained fabrics. 
If a fabric is constrained by the manufacturing process, such as thermoforming or RTM, the geometric changes may not be the same. Additionally, textile deformations observed during the forming of complex composite parts are rarely contributed to pure shear. The fabric generally experiences a combination of shear, tensile, and bending deformations. Future studies should be dedicated to investigating multiple forming conditions, such as constrained thicknesses or complex loading.

\section{CONCLUSIONS}

During the manufacture of textile-reinforced composites, the fabric reinforcement will shear to conform to any complex curvatures present in the mold. This fabric shear was experimentally observed to have a measurable influence on the overall stiffness of the formed part. The individual factors that could be major contributions to the overall stiffness were identified and their significance was explored. The major changes within the reinforcement geometry that were identified to result from fabric shearing were (1) the reorientation of the fibers within the plane of the plate, (2) the increase in plate thickness with increasing shear angle, and (3) the change in the tow cross-sectional shape and orientation as a result of the fabric shear. The flexural behavior of the plates demonstrated a significant dependence on both the reorientation of the fibers within the plane of the plate and the increase in thickness of the plates. No significant dependence on the change in shape or orientation of the fiber tows was observed.

\section{Acknowledgements}

The authors would like to acknowledge the National Science Foundation for its support of this research through Award No. 1230884.

\section{REFERENCES}


[1]. Brøndsted P, Lilholt H, Lystrup A. Composite materials for wind power turbine blades. Annu Rev Mater Res. 2005;35:505-38.

[2]. Jones RM. Mechanics of composite materials: CRC Press; 1998.

[3]. Shivakumar KN, Swaminathan G, Sharpe M. Carbon/vinyl ester composites for enhanced performance in marine applications. Journal of Reinforced Plastics and Composites. 2006;25(10):1101-16.

[4]. Veers PS, Ashwill TD, Sutherland HJ, Laird DL, Lobitz DW, Griffin DA, et al. Trends in the Design, Manufacture and Evaluation of Wind Turbine Blades. Wind Energy. 2003;6(3):24559.

[5]. Hoa SV. Principles of the Manufacturing of Composite Materials. DEStech Publications; 2009.

[6]. Hyer MW, White SR. Stress Analysis of Fiber-reinforced Composite Materials: DEStech Publications, Incorporated; 2009.

[7]. Strong AB. Fundamentals of Composites Manufacturing - Materials, Methods, and Applications (2nd Edition). Society of Manufacturing Engineers (SME); 2008.

[8]. Bhattacharyya D. Composite sheet forming: Elsevier; 1997.

[9]. Friedrich K, Hou M, Krebs J. Thermoforming of continuous fibre/thermoplastic composite sheets. Composite Materials Series. 1997;11:91-162.

[10]. Mallick PK. Fiber-reinforced composites: materials, manufacturing, and design: CRC press; 1993.

[11]. Cao J, Akkerman R, Boisse P, Chen J, Cheng H, De Graaf E, et al. Characterization of mechanical behavior of woven fabrics: experimental methods and benchmark results. Composites Part A: Applied Science and Manufacturing. 2008;39(6):1037-53.

[12]. Lussier D, Chen J. Material characterization of woven fabrics for thermoforming of composites. Journal of Thermoplastic Composite Materials. 2002;15(6):497-509.

[13]. Bel S, Hamila N, Boisse P, Dumont F. Finite element model for NCF composite reinforcement preforming: Importance of inter-ply sliding. Composites Part A: Applied Science and Manufacturing. 2012;43(12):2269-77.

[14]. Carvelli V, Pazmino J, Lomov SV, Verpoest I. Deformability of a non-crimp 3D orthogonal weave E-glass composite reinforcement. Composites Science and Technology. 2012;73:9-18.

[15]. Chen S, Harper L, Endruweit A, Warrior N. Formability optimisation of fabric preforms by controlling material draw-in through in-plane constraints. Composites Part A: Applied Science and Manufacturing. 2015;76:10-9.

[16]. Dangora L, Hansen C, Mitchell C, Parker J, Sherwood J. Challenges Associated with Shear Characterization of a Cross-ply Thermoplastic Lamina using Picture Frame Tests. Composites Part A: Applied Science and Manufacturing. submitted for publication.

[17]. McGuinness G, ÓBrádaigh C. Characterisation of thermoplastic composite melts in rhombusshear: the picture-frame experiment. Composites Part A: Applied Science and Manufacturing. 1998;29(1):115-32.

[18]. Mohammed U, Lekakou C, Dong L, Bader M. Shear deformation and micromechanics of woven fabrics. Composites Part A: Applied Science and Manufacturing. 2000;31(4):299-308.

[19]. Prodromou A, Chen J. On the relationship between shear angle and wrinkling of textile composite preforms. Composites Part A: Applied Science and Manufacturing. 1997;28(5):491-503.

[20]. Zhu B, Yu T, Tao X. An experimental study of in-plane large shear deformation of woven fabric composite. Composites Science and Technology. 2007;67(2):252-61. 
[21]. Boisse P, Gasser A, Hagege B, Billoet J-L. Analysis of the mechanical behavior of woven fibrous material using virtual tests at the unit cell level. Journal of materials science. 2005;40(22):5955-62.

[22]. Boisse P, Hamila N, Helenon F, Hagege B, Cao J. Different approaches for woven composite reinforcement forming simulation. Int J Mater Form. 2008;1(1):21-9.

[23]. Boisse P, Hamila N, Vidal-Sallé E, Dumont F. Simulation of wrinkling during textile composite reinforcement forming. Influence of tensile, in-plane shear and bending stiffnesses. Composites Science and Technology. 2011;71(5):683-92.

[24]. Cherouat A, Borouchaki H, Giraud-Moreau L. Mechanical and geometrical approaches applied to composite fabric forming. Int J Mater Form. 2010;3(2):1189-204.

[25]. Dangora LM, Mitchell CJ, Sherwood JA. Predictive Model for the Detection of Out-of-Plane Defects Formed during Textile-Composite Manufacture. Composites Part A: Applied Science and Manufacturing. 2015;78:102-112

[26]. Fetfatsidis KA, Mitchell C, Sherwood JA, Harvey E, Avitabile P. Simulating the Manufacturing Process and Subsequent Structural Stiffness of Composite Wind Turbine Blades with and without Defects. Proceedings for the 15th ESAForm Conference. Erlangen, Germany2012. p. 249-54.

[27]. Harrison P, Yu W-R, Long AC. Rate dependent modelling of the forming behaviour of viscous textile composites. Composites Part A: Applied Science and Manufacturing. 2011;42(11):1719-26.

[28]. Jauffrès D, Sherwood J, Morris C, Chen J. Discrete mesoscopic modeling for the simulation of woven-fabric reinforcement forming. Int J Mater Form. 2010;3(2):1205-16.

[29]. Lomov SV, Huysmans G, Luo Y, Parnas R, Prodromou A, Verpoest I, et al. Textile composites: modelling strategies. Composites Part A: applied science and manufacturing. 2001;32(10):1379-94.

[30]. Morris CD, Dangora LM, Sherwood JA. Using LS-DYNA® to Simulate the Thermoforming of Woven-Fabric Reinforced Composites. 13th LS-DYNA® International Conference \& User Meeting: Dearborn, MI; 2014.

[31]. Peng X, Cao J. A continuum mechanics-based non-orthogonal constitutive model for woven composite fabrics. Composites part A: Applied Science and manufacturing. 2005;36(6):85974.

[32]. Sharma S, Sutcliffe M. A simplified finite element model for draping of woven material. Composites Part A: Applied Science and Manufacturing. 2004;35(6):637-43.

[33]. Sherwood JA, Jauffres D, Fetfatsidis K, Winchester D, Chen J. Mesoscopic finite element simulation of the compression forming of sheet molding compound woven-fabric composites. 9th Annual Automotive Composites Conference and Exhibition, ACCE 2009, September 15, 2009 - September 16, 2009. Troy, MI, United states: SPE Automotive and Composites Division; 2009. p. 847-63.

[34]. Sidhu R, Averill R, Riaz M, Pourboghrat F. Finite element analysis of textile composite preform stamping. Composite structures. 2001;52(3):483-97.

[35]. Skordos AA, Monroy Aceves C, Sutcliffe MP. A simplified rate dependent model of forming and wrinkling of pre-impregnated woven composites. Composites Part A: Applied Science and Manufacturing. 2007;38(5):1318-30.

[36]. Ten Thije R, Akkerman R, Huetink J. Large deformation simulation of anisotropic material using an updated Lagrangian finite element method. Computer methods in applied mechanics and engineering. 2007;196(33):3141-50. 
[37]. Mitchell C, Sherwood J , Fetfatsidis K, Dangora L. Characteriziation of Cured NCF Composites used in the Forming of Wind Turbine Blades. $19^{\text {th }}$ International Conference on Composite Materials: Montreal, Canada; 2013.

[38]. Mitchell C, Dangora L, Bielmeier C, Sherwood J. Investigation into the Changes in Bending Stiffness of a Textile Reinforced Composite due to In-Plane Fabric Shear: Part 1 Experiment. Composites Part A: Applied Science and Manufacturing. submitted for publication.

[39]. Barbero EJ. Introduction to composite materials design: CRC press; 2010.

[40]. McBride T, Chen J. Unit-cell geometry in plain-weave fabrics during shear deformations. Composites science and technology. 1997;57(3):345-51.

[41]. Twintex(R) Thermoplastic Polypropylene Glass Roving. www.fiberglassindustries.com: Fiber Glass Industries; 2014. 


\section{FIGURES}

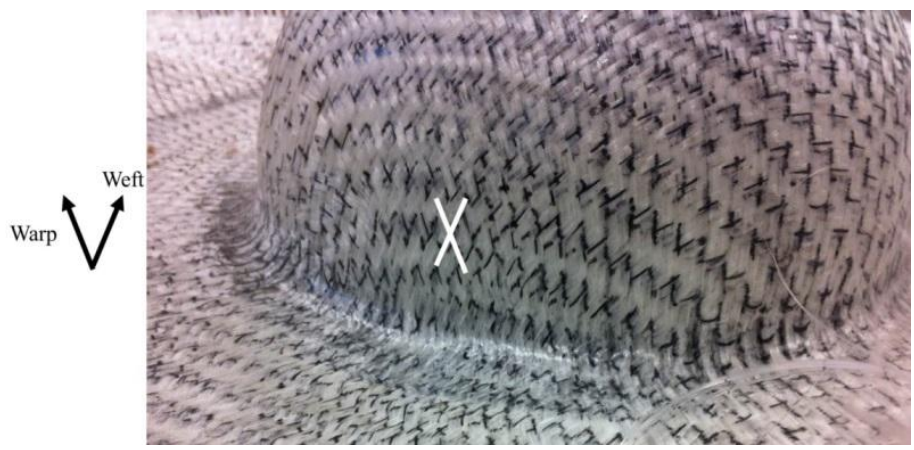

Fig. 1. Shear deformation of a woven fabric formed into a hemisphere.

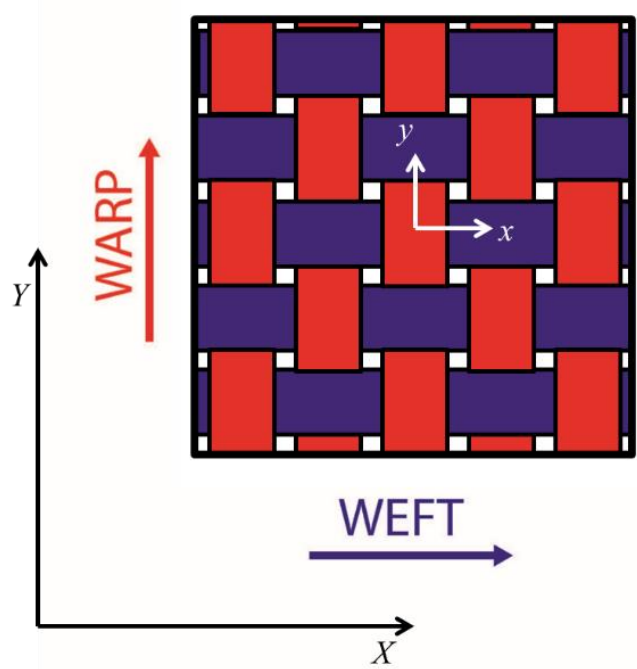

(a)

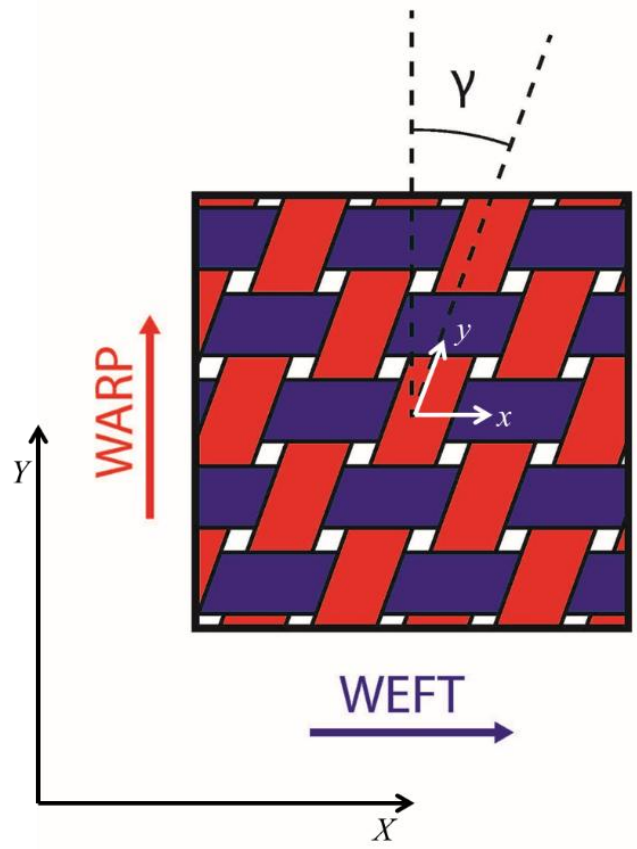

(b)

Fig. 2. Local $x y$ and global XY coordinate systems depicted for (a) undeformed textiles and (b) textiles with a shear deformation equal to $\gamma$ 


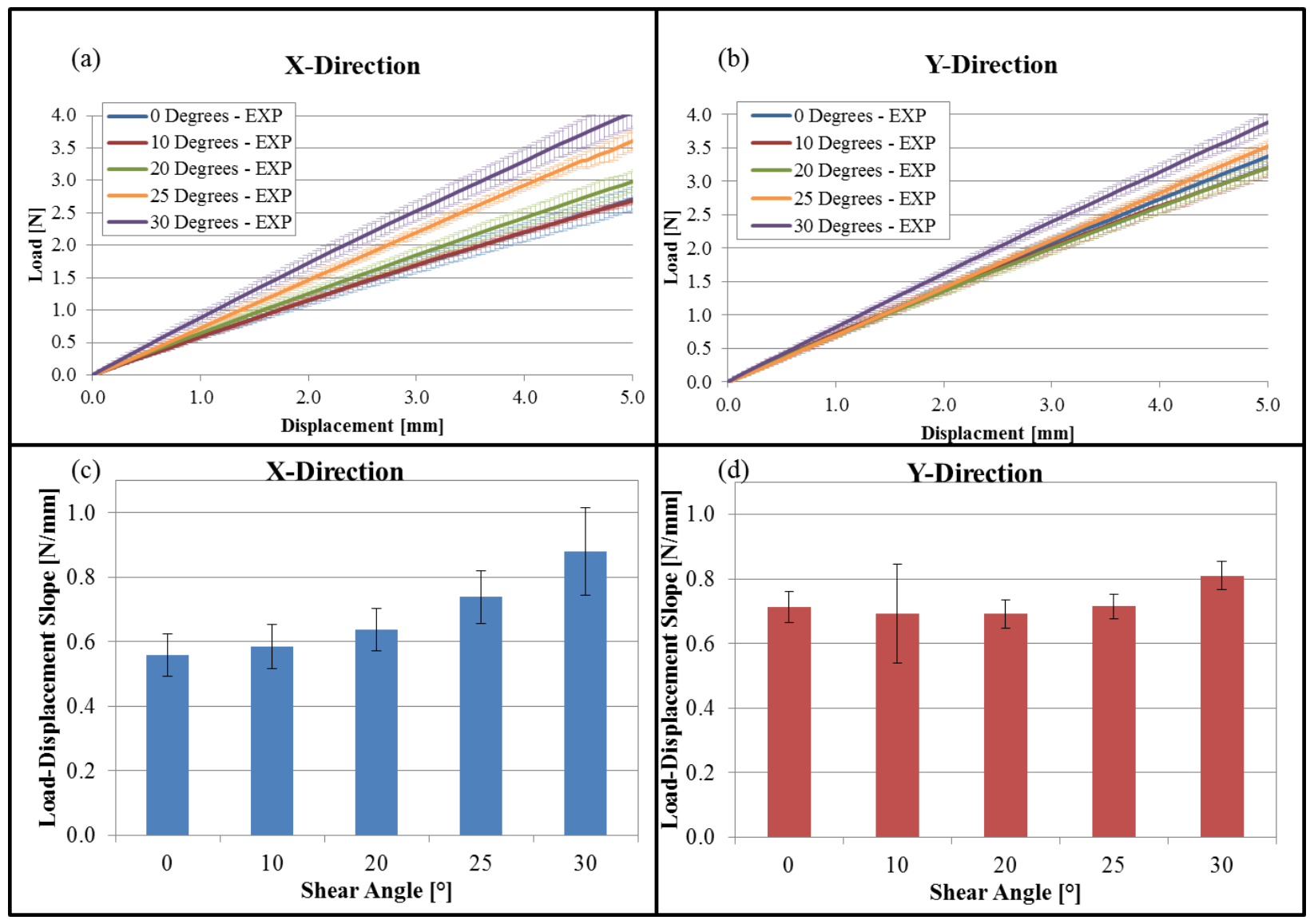

Fig. 3. Bend test load-displacement results for (a) X-direction and (b) Y-direction and the slopes of the load-displacement curves for (c) X-direction and (d) Y-direction 


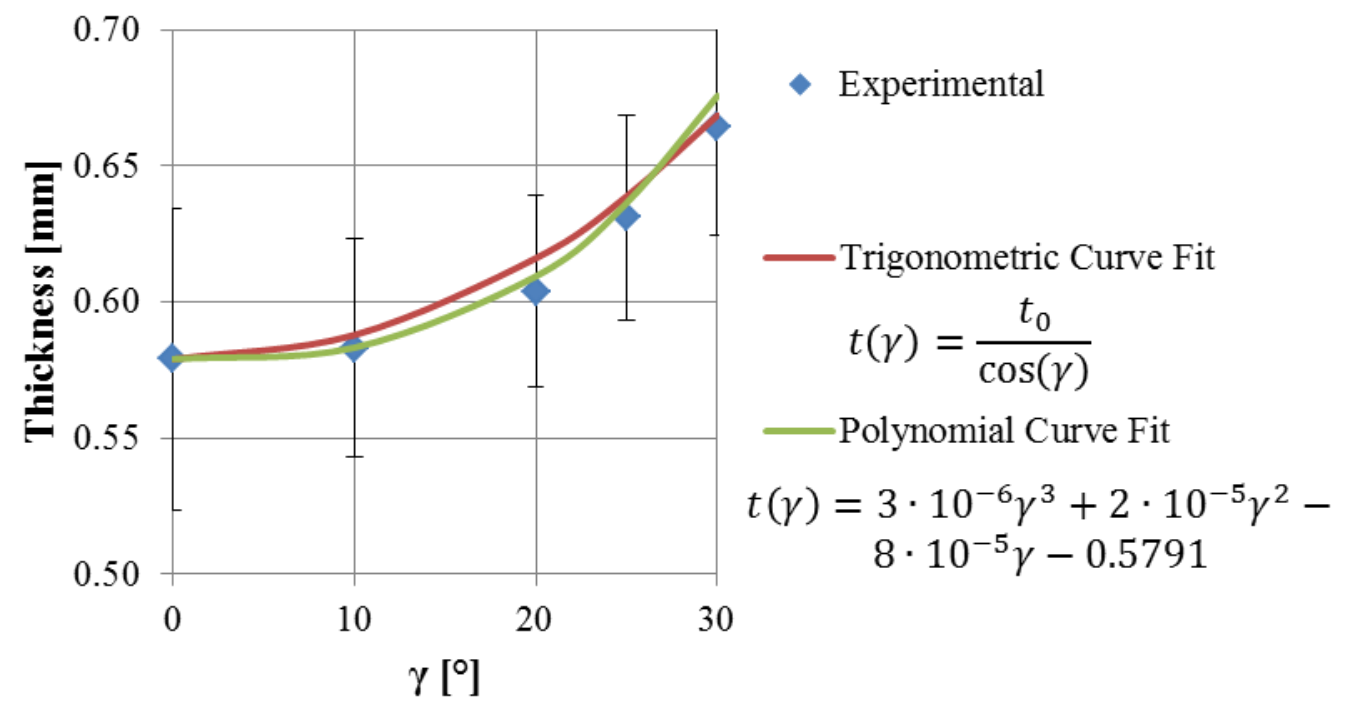

Fig. 4. Experimental measurements of plate thicknesses as a function of reinforcement shear angle compared to two possible functions to describe the data.

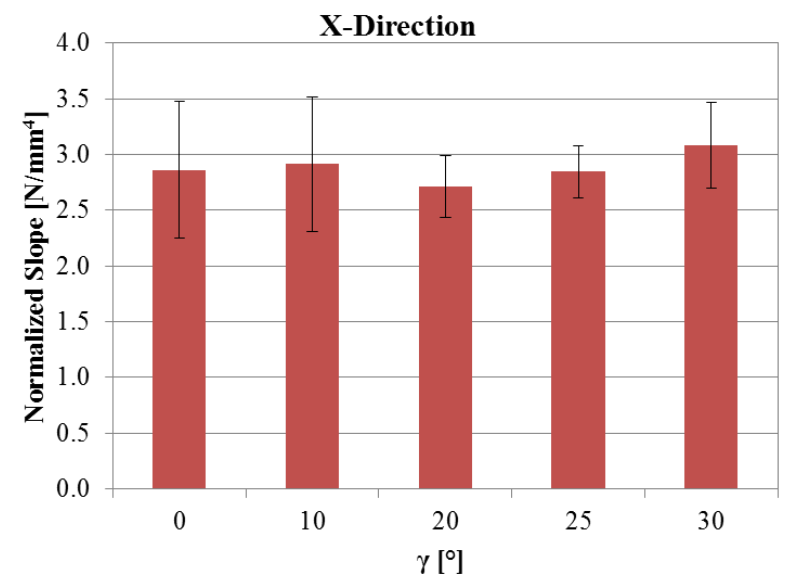

(a)

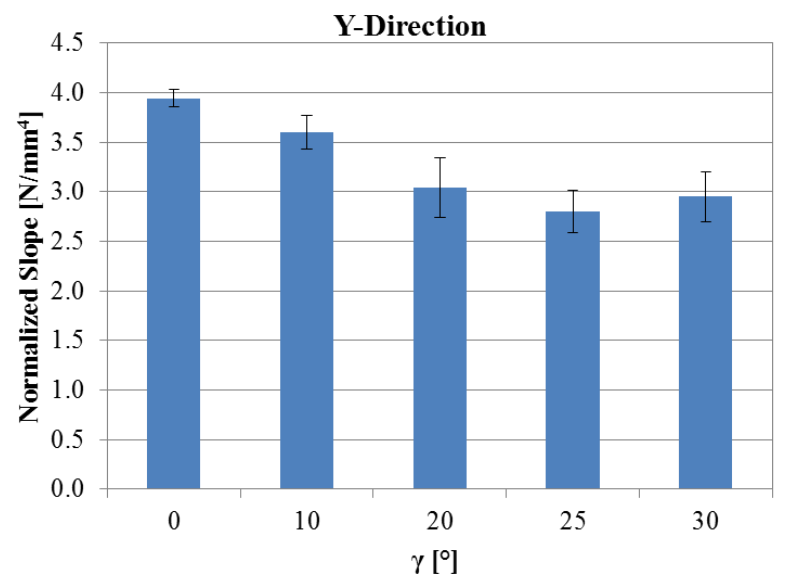

(b)

Fig. 5. Slope of experimental load-displacement curves normalized by cubed thickness for (a) Xdirection and (b)Y-direction. 


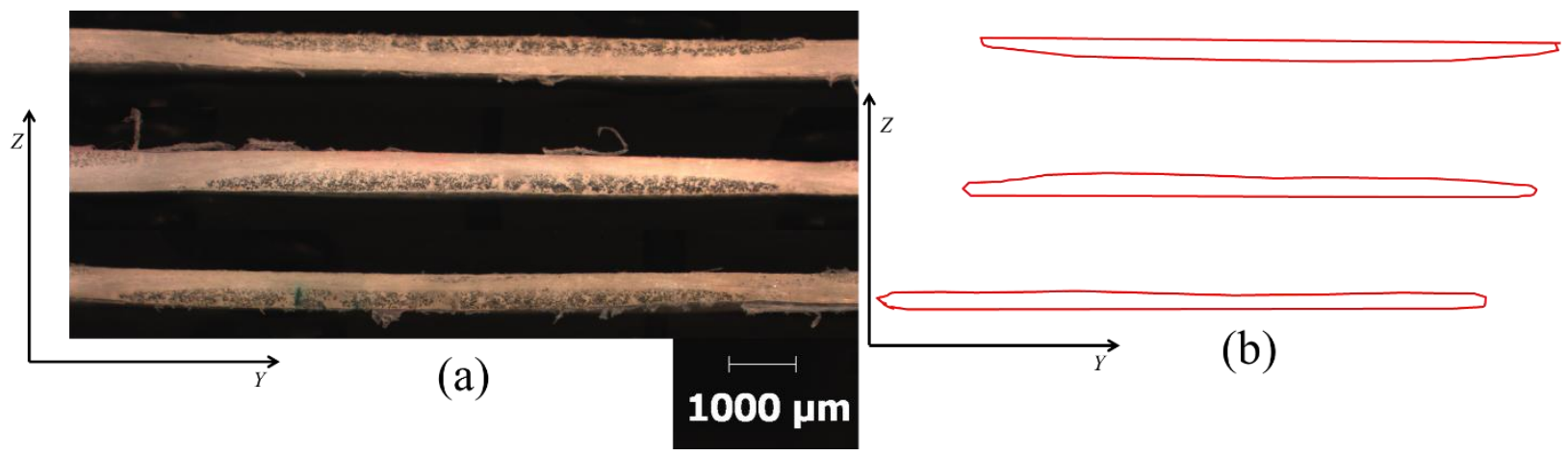

Fig. 6. Y-Y Cross-section of the weft tows with $0^{\circ}$ shear angle in the fabric reinforcement (a) microscope photographs of three different cross-sections and (b) approximate cross-section boundary.

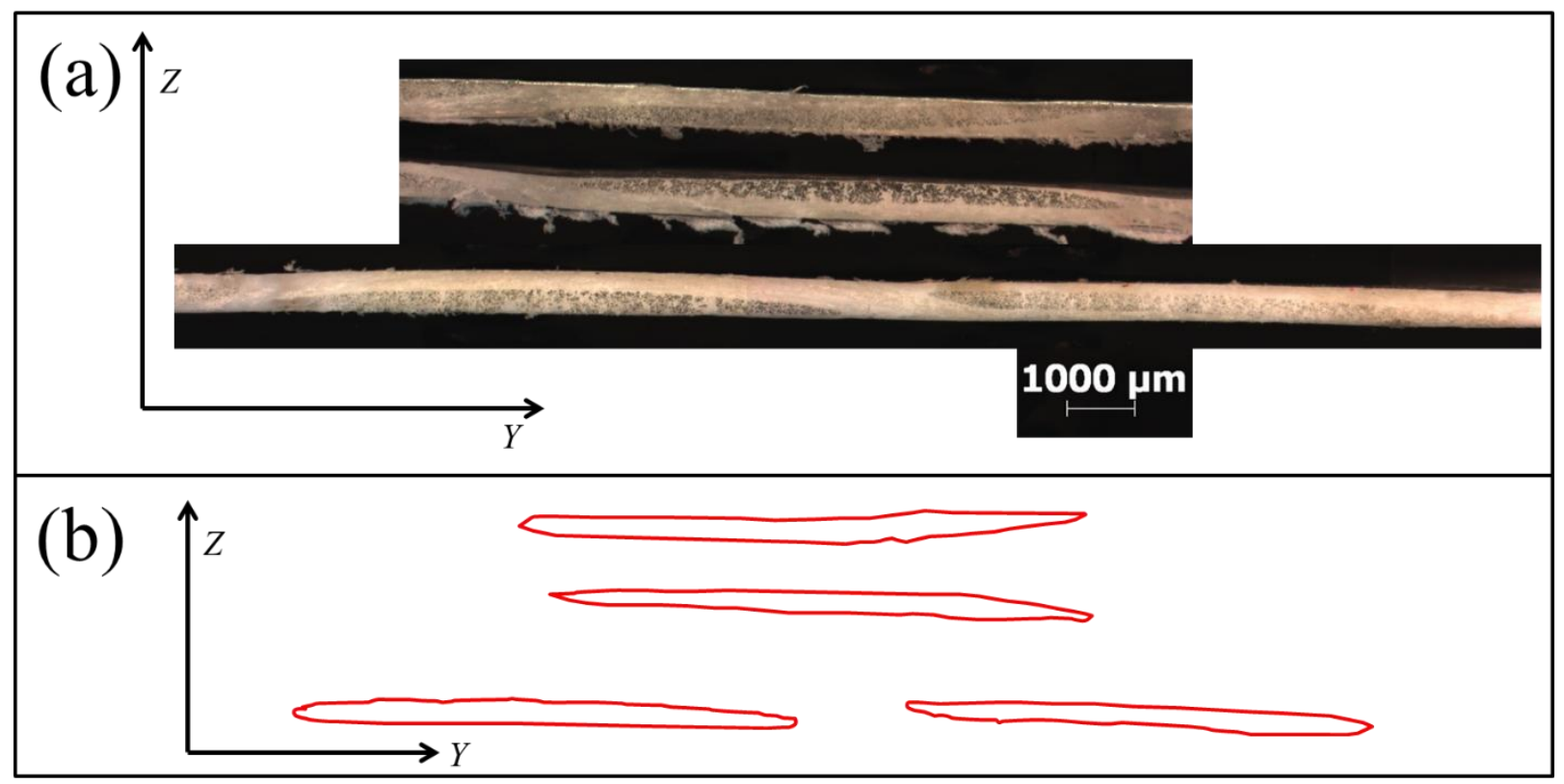

Fig. 7. Y-Y Cross-section of the weft tows with $25^{\circ}$ shear angle in fabric reinforcement (a) microscope photograph s of three different cross-sections and (b) approximate cross-section boundary. 

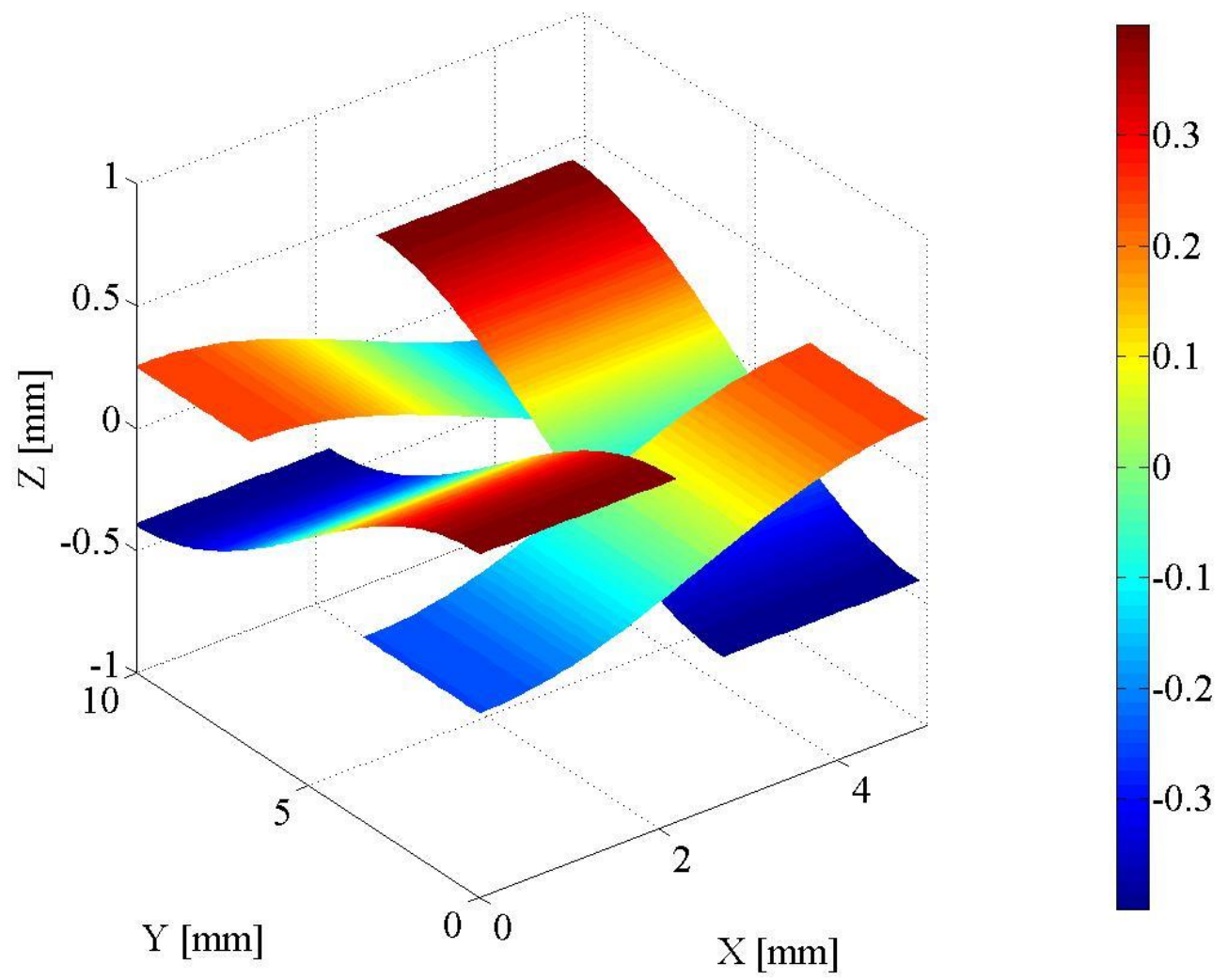

Fig. 8. Representative volume element comprised of tow midsurfaces. 
(a)

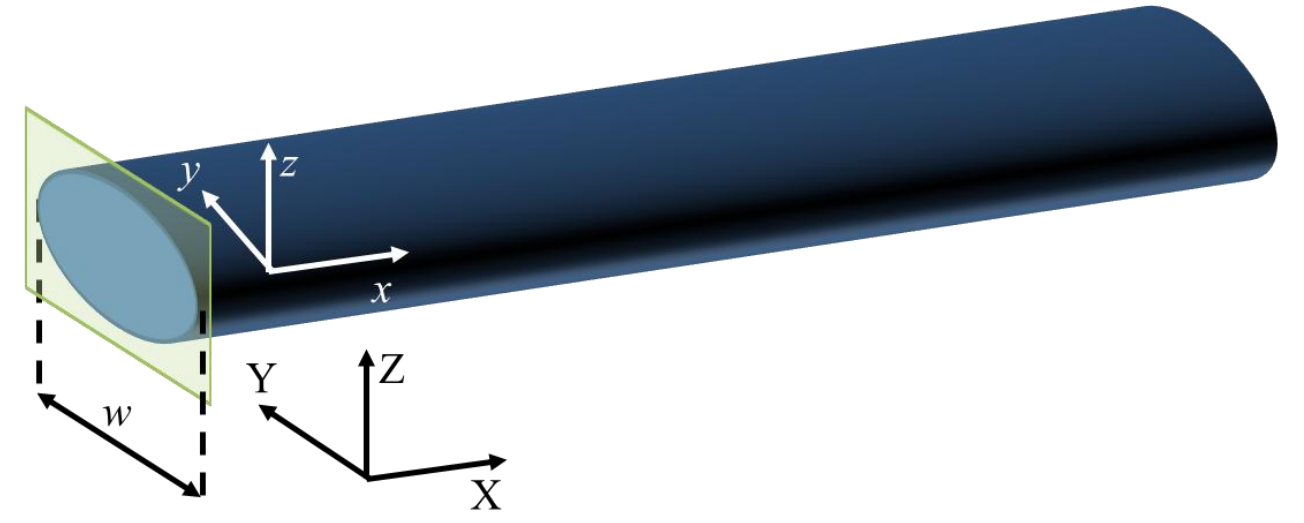

(b)

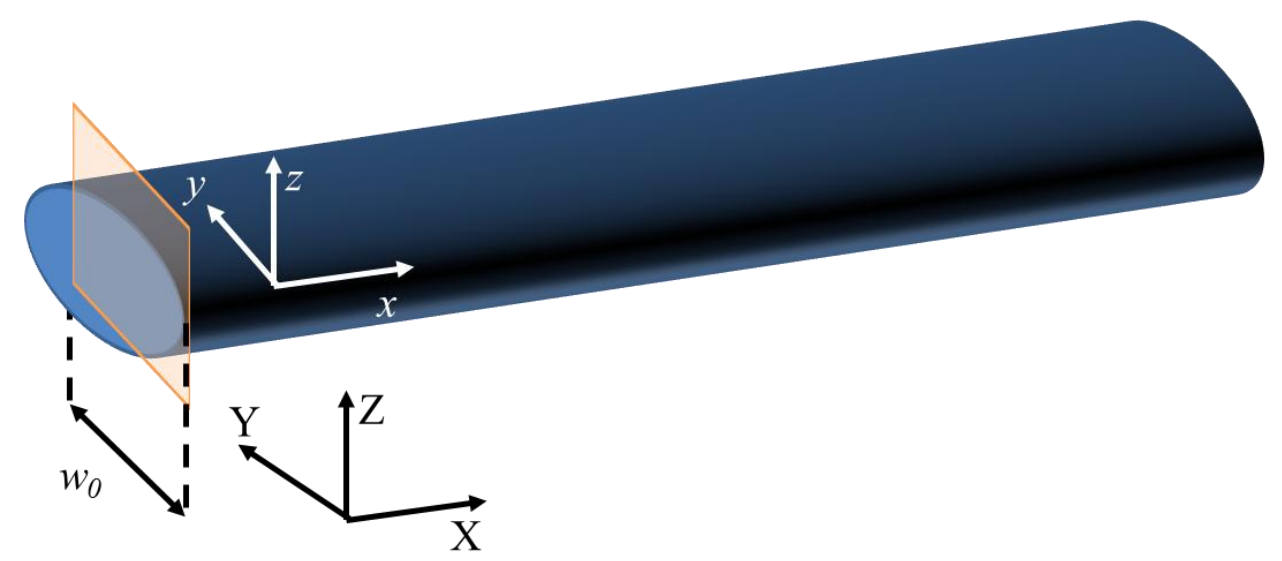

(c)

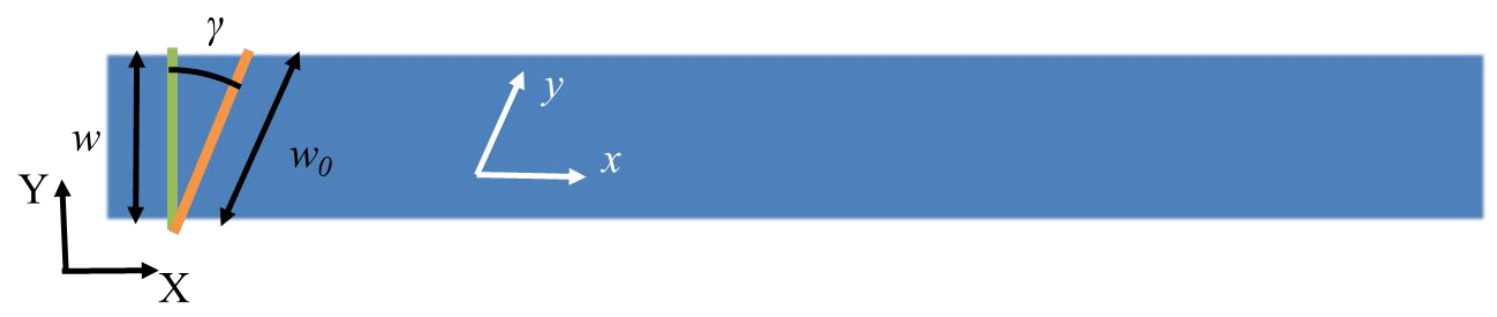

Fig. 9. Schematic of global XYZ coordinate system and local $x y z$ coordinate system for a fiber tow highlighting (a) the global Y-Y cross-section (green), (b) the local $y$ - $y$ cross-section (orange), and (c) the geometric relationship between the Y-Y (green) and $y-y$ (orange) cross-sections 


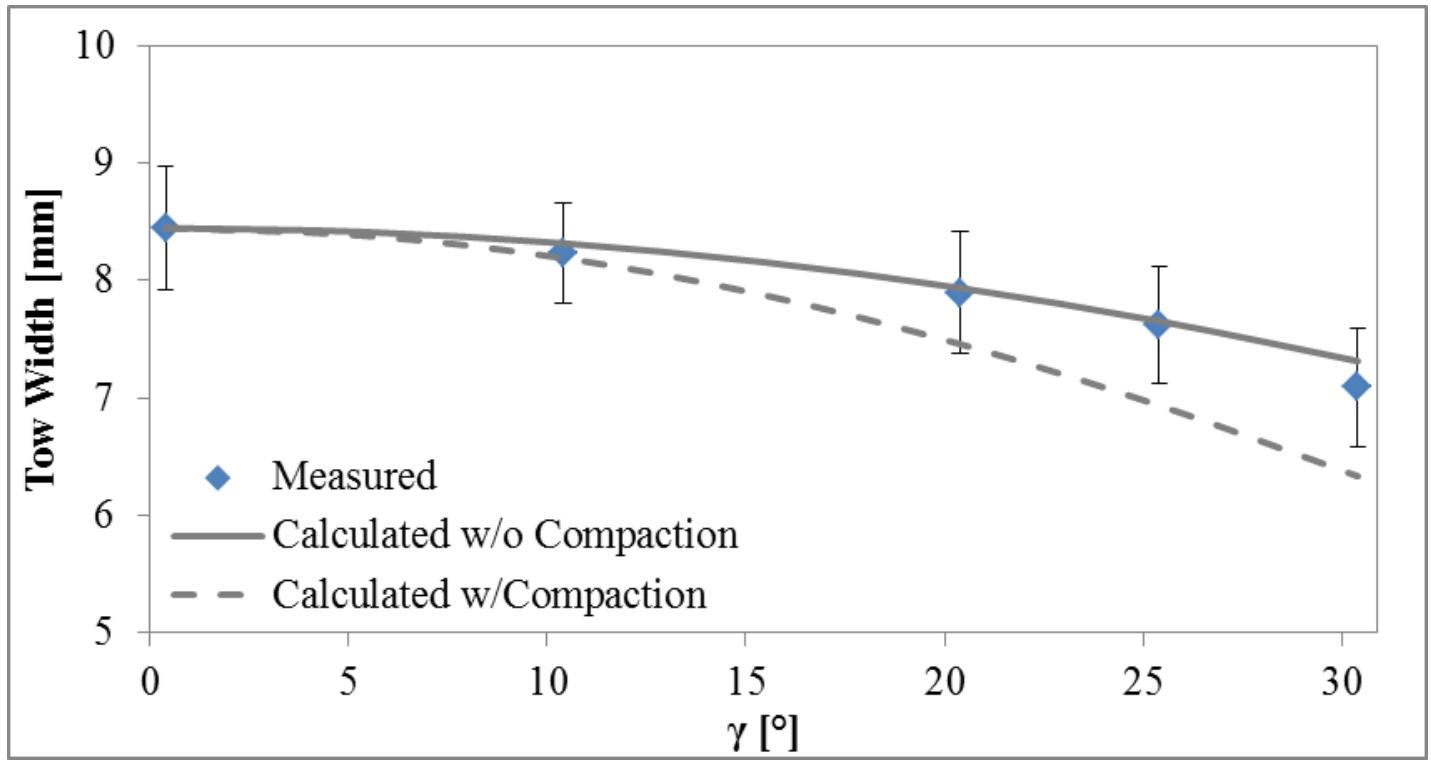

Fig. 10. Weft tow width as a function of reinforcement shear angle. 
(a)

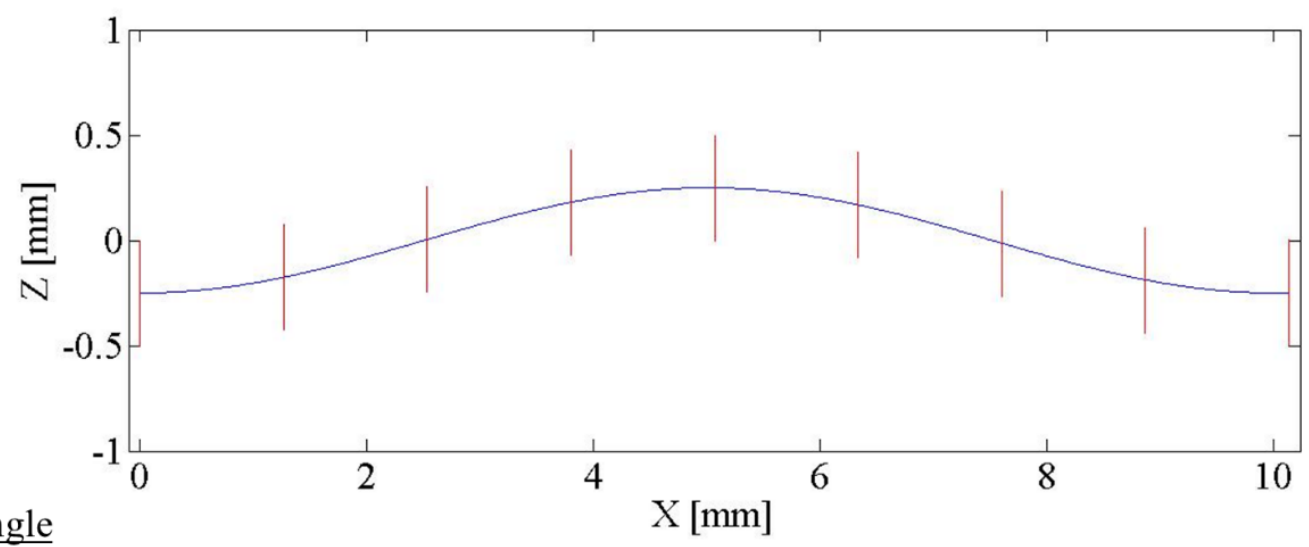

(b) Shear Angle

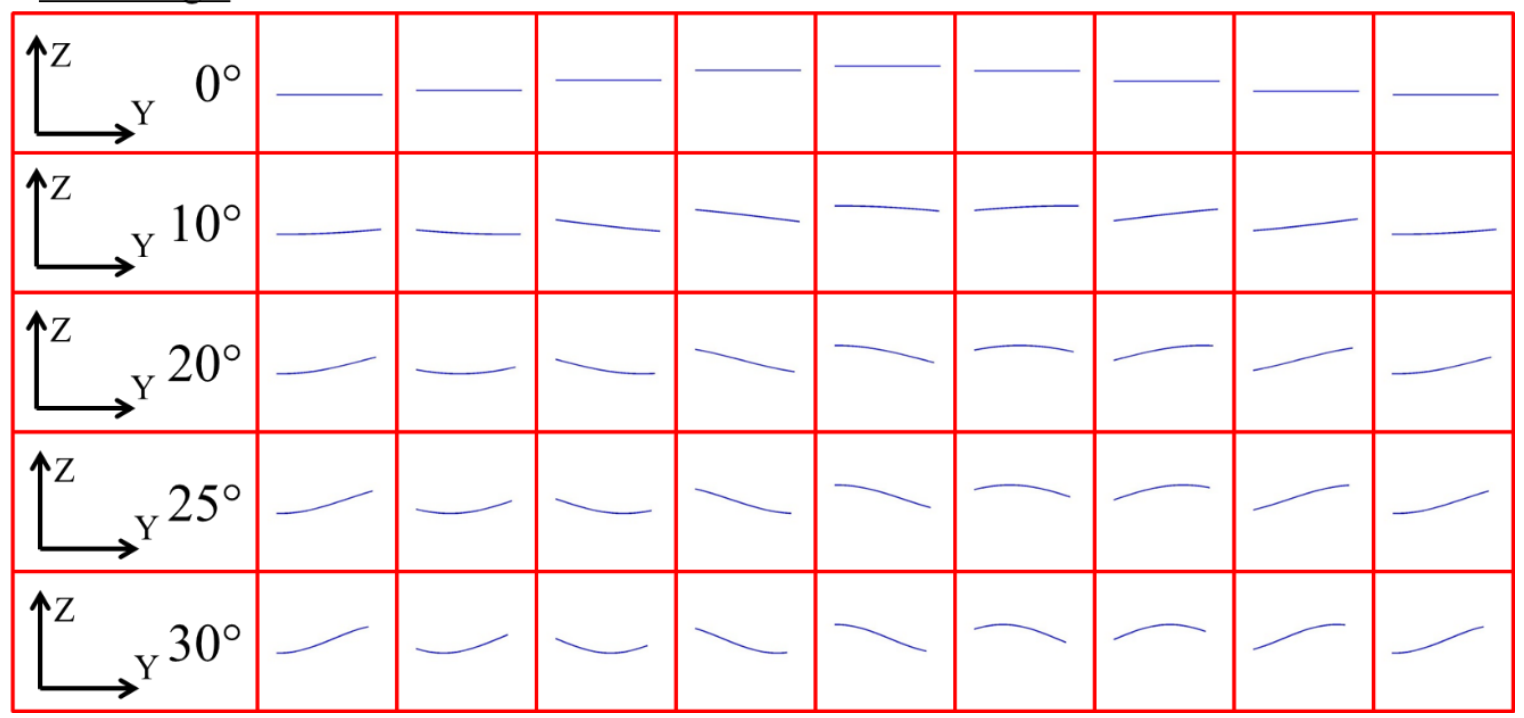

Fig. 11. Variation in cross-section vertical position and orientation along the length of a tow undulation period as a function of shear angle.

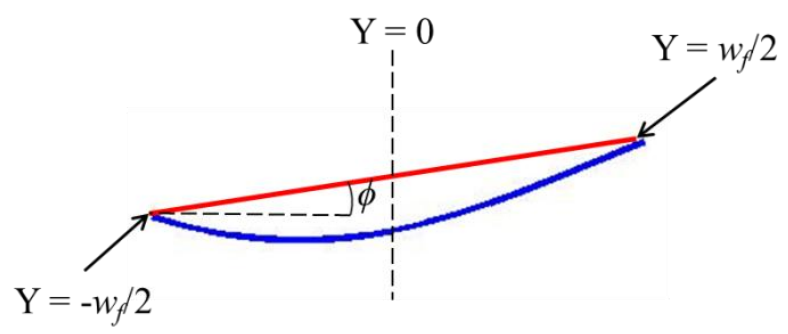

Fig. 12. Schematic of cross-section twist approximation to be implemented into a beam element (red) for the calculated midplane deflection (blue). 


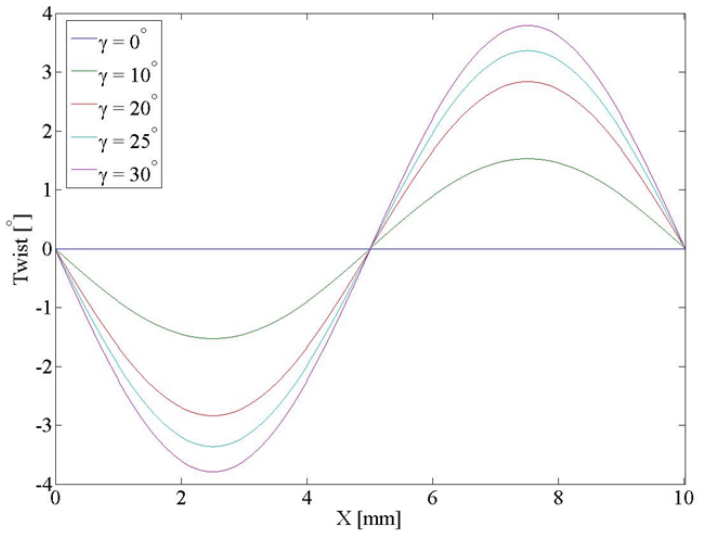

(a)

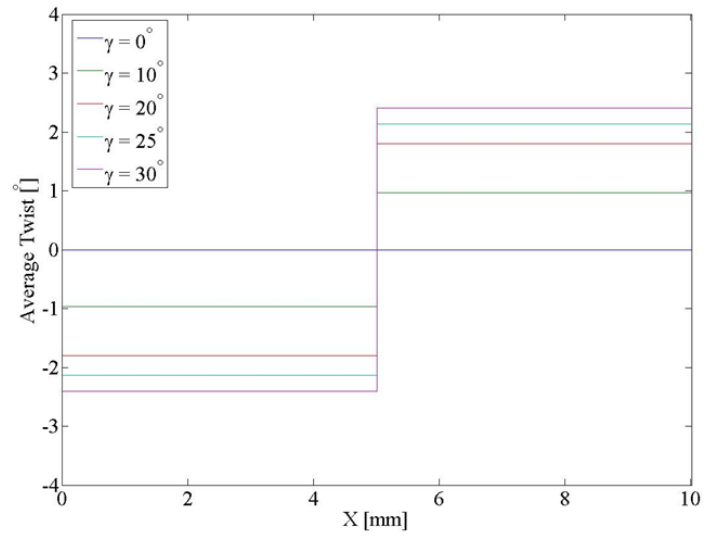

(b)

Fig. 13. Twist angle of cross section: (a) calculated along an undulation period and (b) averaged over the unit cell.

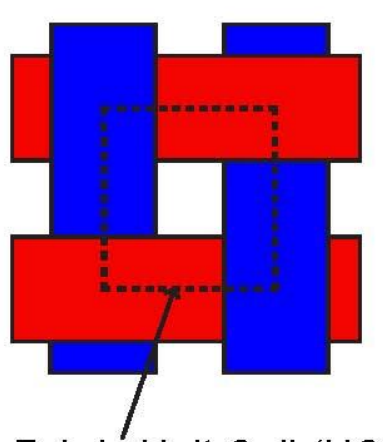

Fabric Unit Cell (UC) elements

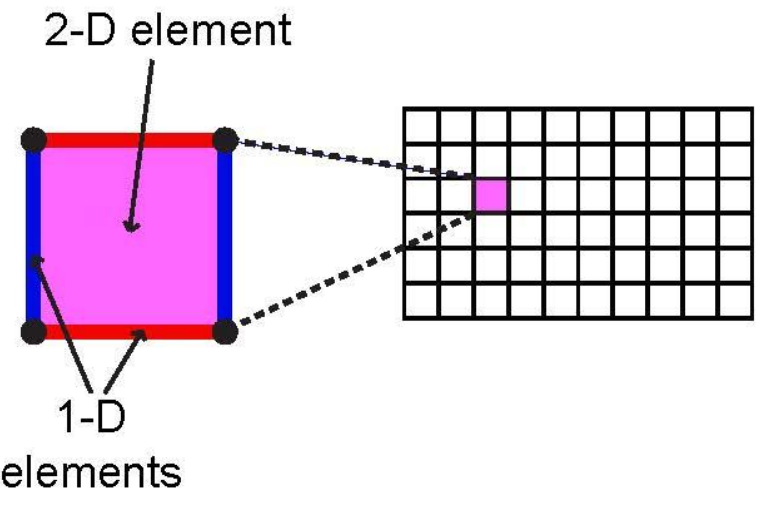

Fig. 14. Finite element approach used to discretely represent a woven-fabric-reinforced composite. 


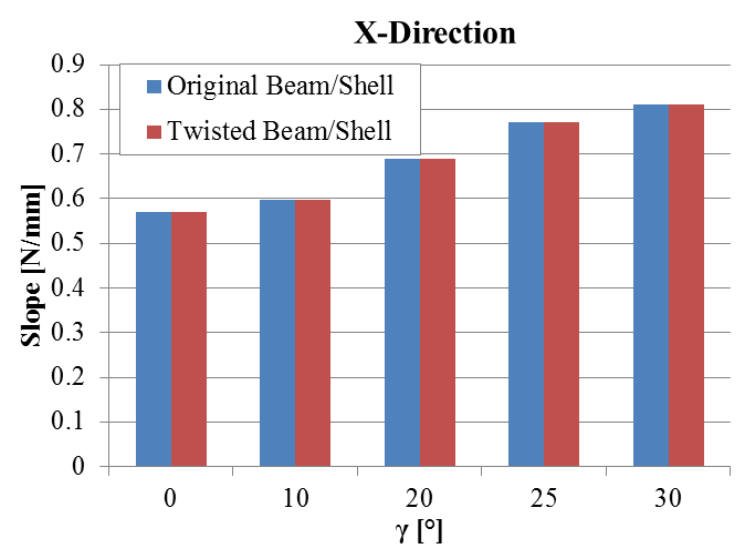

(a)

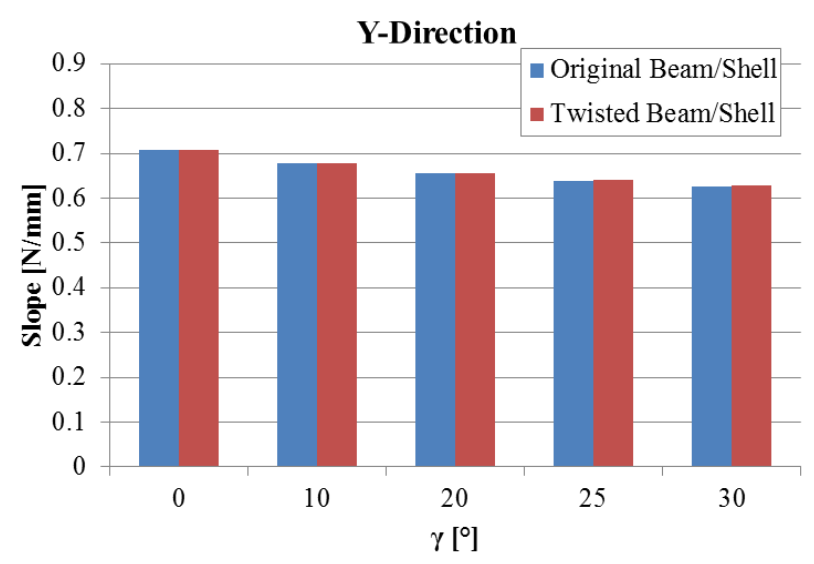

(b)

Fig. 15. Calculated load-displacement curves for three-point-bend tests of beam-shell models with and without beam cross-section twist in (a) the global X-direction and (b) the global Y-direction 


\section{TABLES}

Table 1. Beam-Shell model material properties defined by Twintex ${ }^{\circledR}$ manufacturer's specifications [40].

\begin{tabular}{|l|r|}
\hline$E_{\text {glass }}[\mathrm{MPa}]$ & 70000 \\
\hline $\mathrm{E}_{\text {resin }}[\mathrm{MPa}]$ & 1950 \\
\hline$v_{\text {glass }}$ & 0.22 \\
\hline$v_{\text {resin }}$ & 0.30 \\
\hline $\mathrm{A}_{\text {glass }}\left[\mathrm{mm}^{2}\right]$ & 0.45 \\
\hline $\mathrm{t}_{\text {resin }}[\mathrm{mm}]$ & 0.62 \\
\hline
\end{tabular}

